\title{
eBay: An Authentic Learning Object
}

\author{
Kirsty Young, University of Technology, Sydney, NSW, AUSTRALIA
}

\begin{abstract}
The Internet has evolved to its current form as a result of user-generated content and interactivity and this phenomenon must be more widely recognised in formal education. This paper proposes that popular websites which are reflective of how society uses the Internet on a daily basis should provide the context for authentic and engaging online learning experiences. This position is established through the integration of three socio-cultural views of learning: Situated Cognition, Distributed Cognition and Activity Theory. The integration of these three theories enables evaluation of the Internet as a mediating tool of authentic activity which is socially constructed and bound. The popular online auction site eBay is used to demonstrate the ideas raised throughout this paper.
\end{abstract}

Keywords: Internet, Authentic Learning, School Education, Online Shopping, Situated Cognition, Distributed Cognition, Activity Theory

\section{Introduction}

$\mathrm{A}$

S A MEDIUM for fostering and supporting informal learning the Internet could possibly be one of our most powerful self-directed learning tools (Imel, 2003). This has certainly been found to be the case with children who are immersed in technology-related activities (SeftonGreen, 2003). Educators should capitalise on the natural engagement of youth with the Internet and equip students with the skills necessary to engage with popular websites that might, to the outside observer, appear fraught with risk and harm. Children and adolescents are using the Internet regardless of schooling, so how should we facilitate their leaming with this tool? One approach is to take account of the socio-cultural theories of learning which suggest that learning occurs when cognitive tools are used to engage people in practices which are valued in everyday activity. This is particularly pertinent given the Internet has evolved to its current form as a result of user-generated content and interactivity. This paper proposes that educators should embrace the authentic applications and content that is naturally available on the Internet and the popular online auction site eBay (www.ebay.com) is used to demonstrate this idea. This position has specifically evolved through the integration of three socio-cultural theories of learning: Situated Cognition, Distributed Cognition and Activity Theory.

This paper commences with discussion of the three theories which have been used to explore Internetmediated activity. The paper then moves to briefly examine some of the limitations currently experienced in trying to integrate popular websites in classrooms today (particularly from an Australian perspective). This is followed with an overview of children and adolescents' informal Internet use, which includes evidence of their engagement in online shopping activities.

The paper then moves to establish eBay as an example of an authentic website which can be used to facilitate culturally relevant learning experiences. The contention here is that components of this site enable functional online learning that reflects the way citizens actually use the Internet. It is asserted that more time should be spent developing educationally sound learning sequences that make use of 'real' websites instead of fabricating online experiences. The argument put forth in this paper is that socially constructed and evolving Internet sites are of significant educational value to facilitate the development of active online citizens.

\section{The Internet and Socio-Cultural Theories of Learning}

Three socio-cultural theories are useful for defending the application of popular websites in classrooms: Situated Cognition, Distributed Cognition and Activity Theory. Each of these theories makes its own distinct contribution to understanding the sociocultural nature of learning but exploration of such contributions is beyond the scope of this paper. However, there is sufficient overlap in three areas that makes their integration a powerful theoretical position upon which to build a solid argument for the use of popular websites (such as eBay) in formal education. The three areas are tool-mediation, authentic activity and learning bound by social context.

The integration of Distributed Cognition and Activity Theory results in an understanding of two types of mediating-tools: internal (psychological) tools and external (technical) tools, either of which 
their advantage to continue their development as active online global citizens. These sites should not be avoided because of perceived potential danger of predators and fraud, but instead be embraced for the culturally valued learning experiences they can provide.

What is needed are more educational experiences which demonstrate the meaning of acceptable use of popular websites. Scaffolding students to recognise the dangers and help them develop the skills necessary to be proactive in avoiding the pitfalls but harnessing the benefits of individual websites.

Kafal, Nixon \& Burnam (2007) logically suggest that teachers must develop some understanding of how students perceive appropriate use of the Internet. This will enable them to tailor acceptable Internet use policies for their own context rather than merely offering a set of policy regulations. This approach has the potential to result in long-term responsible participation and understanding about methods to navigate around dangers on the Internet (Meeder, 2005; Kafal et al., 2007)

Indeed, educators actually working with students on a daily basis are best positioned to advise on policy decisions about the use of popular websites in classrooms. While there are certainly pockets of teachers and schools creatively integrating the Internet into their classrooms, unfortunately the attitudes of some toward the integration of the Internet into the education curriculum can be problematic.

\section{(b) Teacher Attitudes and Action}

It is acknowledged that some excellent initiatives have been introduced to make effective use of the Internet, such as the use of learning objects. Learning objects are instructional materials available on the Internet that support student learning and achievement of specific outcomes and can be used in a variety of contexts, by many people and at multiple locations (Cramer, 2007). Extensive portals or repositories have been developed to store and organise learning objects (eg. Thinkport, IDEAS, MERLOT) and these make a valuable contribution toward the design of engaging online learning experiences.

Similarly, there are numerous educationally sound websites brimming with online activities and experiences to enhance learning. For example, Limson, Witzlib \& Desharnais (2007) report on The Virtual Courseware website which has a free suite of innovative, experimental simulations that emphasise the inquiry process. However, while valuable, these activities do not reflect the ways everyday citizens use the Internet on a daily basis. The contention here is that it is worth investing in the development of learning activities around culturally valued (and in many instances culturally-created) popular websites.
While we do see the use of popular websites incorporated in some areas of formal education this is often at the tertiary education level. Trier (2007), for example, integrates YouTube into his graduate course. In this instance, students are required to search for YouTube videos that articulate ideas found in the required weekly readings. However, while there are unique instances of innovative uses of popular websites it does not appear these activities are sufficiently widespread given the proportion of the population who are actually engaging with these websites outside formal educational settings.

While some teachers certainly value the potential of the Internet this does not necessarily translate into good practice. Madden, Ford, Miller \& Levy (2006) report on the perceived usefulness of the Internet by some teachers in the United Kingdom. They conclude that $81 \%$ of respondents regard the Internet as a valuable source of material and $79 \%$ agree that it could make an important contribution to school teaching. However, only $31 \%$ of teachers surveyed often use the Internet in their teaching. Similarly, Tondeur, van Braak \& Valcke (2007) report the behaviours of 352 teachers who were asked to rate statements about the frequency of different types of computer use within their classrooms. Interestingly, the researchers stated that innovative use of computers in these classrooms was so limited they did not factor it into their analysis of classroom use.

It appears that many teachers evaluate the Internet in terms of its 'content' and are primarily concerned whether the material is reliable. Often they are teaching a limited skill set, such as sending emails and searching for information (Madden, Nunes, Ford, McPherson \& Miller, 2003). Many teachers are using the Internet in old familiar ways, rather than amending their teaching practices to reflect the Web 2.0 phenomenon.

To develop useful Internet-mediated learning experiences, teachers must move beyond isolated internet skill development and instead purposefully integrate popular websites in a cross-curriculum learning experience. Tondeur et al (2007) report a number of studies that suggest that while the use of computers in education is increasing, computers are rather poorly integrated into the teaching and learning process. Cramer (2007) identifies three phases of technology integration:

Phase I Print Automation: computers replace what could be accomplished on paper or by hand.

Phase II expansion of learning opportunities: students and teachers use technology in its tutorial format to collect information, carry on dialogues with people from around the world, power of the Internet for research and use of learning objects 
To this point a theoretical argument has been made to support the use of popular websites in formal education to enable students to engage with a culturally valued cognitive tool (the Internet) in a manner reflective of daily use by citizens. It has been proposed that this would enable students to engage in authentic, goal directed activity to develop their skills as active online citizens. This argument was supported by a critique of some of the limitations of Internet use in classrooms and by highlighting children's Internet usage outside the formal school environment. The paper now moves forward to describe the forms of learning primarily evidenced by an 11 year old Australian boy whilst he was using eBay. Following this a series of simple classroom activities that demonstrate ways eBay can be used to facilitate student learning are then identified.

\section{eBay as an Authentic Learning Experience}

\section{What is eBay and how does it Work?}

Peirre Omidyar founded eBay in September 1997 to help his then fiancé collect confectionary 'pez' dispensers and now, a decade on, it is well established as a popular global website. eBay reports a customer base of 233 million across 37 countries trading more than US\$1,830 per second. eBay enables individuals and companies to list items to be auctioned and sold to the highest bidder or sold immediately through a buy-it-now option. The process is significantly reliant on reputation where both buyer and seller are encouraged to leave feedback about each transaction.

Criticisms of eBay generally relate to issues of fraud and intellectual property violations. Fraud, when committed by the seller, can include such things as not shipping goods after payment, giving a misleading description or selling counterfeit items. Fraudulent acts engaged by the buyer could include claiming that he/she has not received the item or using a stolen credit card to make purchases. Clearly, online security should form an integral part of any curriculum. Indeed, eBay is aware that its users need to be warned about possible dangers and have developed an educational program using various cartoon characters to highlight the dangers. The eBay organisation has developed eight tips - each of which can be a lesson in itself. More detailed information is available at www.ebay.com.au/securitycentre/.

Researchers have also identified additional risks involved in online shopping in a global marketplace. The large variety of dangerous poisons readily available. Similarly, inappropriate material is reported by Parish (2004), in the form of nursing students' essays which are being traded for money.
However, as will be shown later in this paper, these negative experiences can be harnessed as valuable learning experiences.

\section{The Potential of eBay as an Education Tool}

As identified earlier, the impetus for this paper was a study conducted by the author in $2003 / 04$. The children in that study were asked to 'think-aloud' while they used the Internet in a way that was reflective of the way they would use it at home. The 'thinkaloud' process involved the participants continuously speaking aloud the thoughts in their head as they worked on their chosen online activity (for detail of this qualitative research method see Ericsson \& Simon, 1993; Young, 2005). During this process one 11 -year old boy chose to 'think aloud' while exploring eBay. Analysis of his 'think aloud' data lead to follow-up interviews with the other child participants and enabled further exploration of their experiences and understanding of online shopping in a global world. Data obtained which was specifically related to the use of eBay identified the following forms of learning to be evident.

(a) Awareness of the impact of global distances on online shopping

When discussing problems associated with online purchases Yanni was clearly aware of issues related to time and distance when he concluded that if he didn't get his purchase "in three weeks ... longer depending where it is coming from ..." (think-aloud: 19.09.03) he would send an email.

Both Nate and Yanni also raised the issue of postage across global distances:

“...sometimes you get suckered in because it might come over from a different country and you need to pay for postage and handling" (Nate) (interview: 11.05.04).

"... but you would have to pay for shipping .... it isn't normally heaps but sometimes it can be more than the actual product" (Yanni) (interview: 11.05.04).

\section{(b) Economic viability of buying/selling online}

Yanni also demonstrated a good understanding of the economic viability of different approaches to buying and selling. For example, when comparing the 'auction' and 'buy-it-now' options on eBay he suggests "... you might get the thing cheaper by auction but the buy-it-now means you can have it straight away" (think-aloud: 19.09.03).

Yanni had previously acknowledged the value in selling something you could not use on eBay but at 


\begin{tabular}{|c|c|}
\hline Mathematics & $\begin{array}{l}\text { (a) Students are given a context and a budget (eg. furnish a home for } \$ 1000 \text { ). They must } \\
\text { identify priority needs and then scour recent sales and identify and justify what would have } \\
\text { been the 'best buys' to achieve their contextual goal. } \\
\text { (b) For a selection of items students calculate how much it would cost them to post/ship } \\
\text { the items to various locations. } \\
\text { (c) Students access a foreign eBay site and calculate the cost of items based on today's ex- } \\
\text { change rate. } \\
\text { (d) Students undertake comparison of prices of various items when auctioned online or } \\
\text { bought from a store. Highlighting instances where auctions have resulted in higher expense } \\
\text { than buying new from a store. } \\
\text { (e) Students are given various photographs of an item and required to calculate the exact } \\
\text { costs for listing (and subsequently selling) the item. }\end{array}$ \\
\hline Onlir & $\begin{array}{l}\text { (a) Students deconstruct the eBay site and apply meaning to each of the icon symbols used } \\
\text { to negotiate and navigate the site. } \\
\text { (b) Students are taught to 'read between the lines' and identify what is not stated in a given } \\
\text { listing that could affect the quality of the product. } \\
\text { (c) Students analyse the description of a given product and identify questions which should } \\
\text { be asked of the seller to ensure authenticity and quality of the product. } \\
\text { (e) Students write a description to promote a given product (including the use of photographs, } \\
\text { text, font, colour, layout) and justify their choices. } \\
\text { (d) Students review the 'feedback' given on various buyers/sellers and identify common } \\
\text { language features and the use of symbols to 'rate' others. Consider issues of ill-defined } \\
\text { standards which may impact quality of feedback. }\end{array}$ \\
\hline Cult & $\begin{array}{l}\text { (a) Students access various international eBay sites and identify differences across cultures } \\
\text { (eg. types of products listed, feedback given). } \\
\text { (b) Students identify valuable items based on popularity in a given country (eg. baseball } \\
\text { Canada) } \\
\text { (c) Students evaluate goods based on origin of production (eg. quality, human rights) } \\
\text { (d) Students evaluate specific goods which are reflective of popular culture (eg. inflated } \\
\text { pricing for a brand name or celebrity item) }\end{array}$ \\
\hline S & $\begin{array}{l}\text { (a) Students scan the eBay site to identify prohibited items or items they consider inappro- } \\
\text { priate for listing (and justify). } \\
\text { (b) Students scan the eBay site and identify violations of copyright, etc. } \\
\text { (c) Students monitor various items (or sellers) in an attempt to identifying potential shilling } \\
\text { (fake bids to increase the price). } \\
\text { (d) Students undertake detailed analysis of the security of online purchases (eg. through } \\
\text { PayPal, direct debit, cash on delivery). }\end{array}$ \\
\hline History & $\begin{array}{l}\text { (a) Students study the culture of collecting and analyse the value of eBay in promoting such } \\
\text { activities. } \\
\text { (b) Students study particular periods, manufacturers, etc and use eBay to identify valuable } \\
\text { items and estimate a reasonable price based on offline sales. }\end{array}$ \\
\hline Medi & in the popular meala ana make informed comment on the contentious issues. \\
\hline
\end{tabular}

The above suggests twenty-one activities that could be developed using eBay in the form it naturally occurs on the Internet. It does not require manipulation or adaptation of the site, just engagement with it as it appears in its everyday format. The fact that it evolves minute-by-minute makes its use realistic and engaging, rather than the static experience which online activity can sometimes be reduced to.

It would be a simple task for educators to draw out the cross-curricula learning outcomes that could be developed into a learning sequence or unit of work. What should also be considered is asking students themselves to develop activity ideas.

\section{Conclusion}

The suggestion to use an authentic website such as eBay to create educational experiences is grounded in a strong theoretical bases of socio-cultural learning. The activities described above enable students to engage with content that has been created by eBay users and reflects their goal-directed authentic 
NetRatings Australia Pty Limited. (2005). kidsonline@home: Internet use in Australian homes. Prepared by NetRatings Australia Pty Ltd for the Australian Broadcasting Authority and NetAlert Limited. April 2005.

Northcote, M., \& Kendle, A. (undated). Informal online networks for learning: Making use of incidental learning through recreation. Retrieved 22 November, 2004, from http://www.aare.edu.au/01 pap/nor01596.htm

Parish, C. (2004). Student essays for sale on internet auction sites. Nursing Standard. 19(13). 5-9.

Sefton-Green, J. (2003). Report 7: Literature Review in Informal Learning with Technology Outside School: NESTA Futurelab.

Tondeur, J., van braak, J., \& Valcke, M. (2007). Towards a typology of computer use in primary education. Journal of Computer Assisted Learning. 23. 197-206

Trier, J. (2007). 'Cool' engagement with YouTube: Part 2. Journal of Adolescent and Adult Literacy. 50(7). 598-603.

Vishwanath, A. (2003). Comparing Online Information Effects: A Cross-Cultural Comparison of Online Information and Uncertainty Avoidance. Communication Research. 30. 579-598,

Young, K. A. (2005) Direct from the Source: The value of 'think-aloud' data in understanding learning. Journal of Educational Enquiry, 6(1). 19-33.

Young, K. A. (2005) Young, Competent Internet-Users: A Theory-Based Profile. Unpublished doctoral thesis submitted to the University of Technology, Sydney. Available http://epress.lib.uts.edu.au/dspace/bitstream/2100/325/1/01 front.pdf

Young, K. A. (2008) Toward a model for the study of children's informal Internet use. Computers in Human Behaviour Special Edition. 24. 173-184.

\section{About the Author}

Dr. Kirsty Young

Dr. Young is a Lecturer in the Faculty of Arts and Social Sciences at the University of Technology, Sydney. Dr. Young teaches a range of educational practice and research methodology subjects. Dr. Young primarily conducts research in the area of authentic Internet-mediated learning. She has a particular interest in multimodal analysis and the effects of new media on communication and the English language. 